\title{
DOSES DE GESSO EM CAFEEIRO: INFLUÊNCIA NOS TEORES DE CÁlCIO, MAGNÉSIO, POTÁSSIO E pH NA SOLUÇÃo DE UM LATOSSOLO VERMELHO DISTRÓFICO ${ }^{(1)}$
}

\author{
Bárbara Zini Ramos ${ }^{(2)}$, João Paulo Vaz Floriano Toledo ${ }^{(3)}$, José Maria de Lima ${ }^{(4)}$, Milson \\ Evaldo Serafim $^{(5)}$, Ana Rosa Ribeiro Bastos ${ }^{(6)}$, Paulo Tácito Gontijo Guimarães ${ }^{(7)}$ \& Aline \\ Renée Coscione ${ }^{(8)}$
}

\begin{abstract}
RESUMO
O desbalanço entre $\mathrm{Ca}^{2+}, \mathrm{Mg}^{2+} \mathrm{e} \mathrm{K}^{+}$no solo como consequência das aplicações elevadas de gesso deve-se às relações de tamanho (raio iônico) e densidades de cargas (relação carga/raio) de cada espécie iônica. Quanto maior a densidade de carga, mais intensa será a ligação iônica do cátion com íons de cargas opostas como $\mathrm{OH}^{-}$e $\mathrm{SO}_{4}{ }^{-2}$. Dessa maneira, o uso excessivo de gesso agrícola, sem considerar o balanço de cargas das partículas do solo; o equilíbrio iônico; e a CTC podem resultar em expressiva lixiviação ao longo do perfil do solo. $O$ objetivo deste estudo foi avaliar o efeito de elevadas doses de gesso $\left(0,7\right.$ e $\left.56 \mathrm{t} \mathrm{ha}^{-1}\right)$ nos teores de $\mathrm{Ca}^{2+}, \mathrm{Mg}^{2+}$, $\mathrm{K}^{+} \mathbf{e} \mathbf{p H}$ na solução de um Latossolo Vermelho distrófico cultivado com cafeeiro, obtida pelo método adaptado do extrato aquoso. $\mathrm{O}$ solo foi amostrado nas profundidades de $0,15-0,25 ; 0,35-0,45 ; 0,75-0,85 ; 1,15-1,25$ e $2,35-2,45 \mathrm{~m}$ na linha de plantio, em quatro tratamentos: G-0 - gesso no preparo (aplicação ocorreu em setembro de 2008, distribuído a lanço, na quantidade de $2 \mathrm{t} \mathrm{ha}^{-1}$ ) e sem gesso na linha de plantio; G-7 - gesso adicionado durante a preparação do solo $\left(2 \mathrm{t} \mathrm{ha}^{-1}\right)$, na mesma condição do G-0 e 7,0 t ha-1 de gesso na linha de plantio; G-56 - gesso adicionado durante a preparação do solo $\left(2 \mathrm{t} \mathrm{ha}^{-1}\right)$, na mesma condição do G-0 e $56 \mathrm{t} \mathrm{ha}^{-1}$ de gesso na linha de plantio (nessas parcelas experimentais as entrelinhas de plantio foram cobertas com braquiária); e CV-7: ausência de braquiária na
\end{abstract}

(1) Parte da Tese de Doutorado da primeira autora, desenvolvida com suporte financeiro da Fapemig, CNPq e Empresa AP. Recebido para publicação em 14 de setembro de 2012 e aprovado em 20 de maio de 2013.

(2) Doutora em Ciência do Solo, Bolsista CNPq, Departamento de Ciência do Solo, Universidade Federal de Lavras (DCS/UFLA). Caixa Postal 3037. CEP 37200-000 Lavras (MG). E-mail: barbarazini@yahoo.com.br

(3) Discente do curso de Química, UFLA. Bolsista de Iniciação Científica/CNPq. E-mail: quimico.jp@gmail.com

(4) Professor, DCS/UFLA. Bolsista do CNPq. E-mail: jmlima@des.ufla.br

(5) Professor do Instituto Federal de Educação, Ciência e Tecnologia de Mato Grosso, Campus Cáceres. Av. dos Ramires, s/n. Distrito Industrial. CEP 78106-960 Cáceres (MT). E-mail: milson.serafim@cas.ifmt.edu.br

(6) Pós-doutoranda, DCS/UFLA. Bolsista do Programa Nacional de Pós-Doutorado/UFLA/PNPD/CAPES. E-mail: arosa@dcs.ufla.br

(7) Pesquisador da EPAMIG, CEP 37200-000 Lavras (MG). E-mail: paulotgg@epamig.ufla.br

(8) Pesquisadora do Centro de Pesquisa e Desenvolvimento de Solos e Recursos Ambientais, Instituto Agronômico. Bolsista do CNPq. Av. Barão de Itapura, 1481. CEP 13012-970 Campinas (SP). E-mail: aline@iac.sp.gov.br 


\begin{abstract}
entrelinha, com gesso no preparo e $7 \mathrm{t} \mathrm{ha}^{-1}$ de gesso na linha, com três repetições distribuídas em blocos ao acaso, totalizando 60 amostras. Após 16 meses da adição de gesso, observou-se redução do $\mathrm{pH}$ na solução do solo nas profundidades de 0,15 0,25; 0,35-0,45 e 0,75-0,85 m. A aplicação de gesso agrícola foi eficiente na melhoria do ambiente radicular no subsolo, aumentou a concentração de $\mathrm{Mg}^{2+} \mathbf{e ~ C a}^{2+}$ na solução do solo, mas reduziu o $\mathrm{K}^{+} \mathrm{em}$ profundidade, a partir de $0,85 \mathrm{~m}$. Os teores de $\mathrm{Ca}^{2+} \mathbf{e} \mathrm{Mg}^{2+}$ trocáveis na solução do solo estiveram acima do nível crítico; entretanto, os teores de $\mathrm{K}^{+}$trocável se mantiveram na faixa do valor crítico, indicado para o desenvolvimento da cultura.
\end{abstract}

Termos de indexação: cátions básicos, lixiviação, balanço nutricional.

\title{
SUMMARY: GYPSUM APPLICATIONS TO COFFEE: INFLUENCE ON CALCIUM, MAGNESIUM AND POTASSIUM CONTENTS AND pH OF THE SOLUTION OF A DYSTROPHIC RED LATOSOL
}

\begin{abstract}
Unbalanced amounts of $\mathrm{Ca}^{2+}, \mathrm{Mg}^{2+}$ and $\mathrm{K}^{+}$in soils as a consequence of high gypsum applications can be due to the relationship in size (ionic radius) and charge density (charge / ionic radius) of each ionic species. The higher the ionic strength, the stronger is the bonding of these cations with the opposite charge ions such as $\mathrm{OH}^{-}, \mathrm{SO}_{4}^{-2}$. Thus, excessive gypsum applications, disregarding the charge balance of the soil colloidal system, the ionic balance of the solution, and the CEC, can result in significant leaching of these nutrients throughout the soil profile. The aim of this study was to evaluate the effect of high gypsum rates $(0,7$, and $56 \mathrm{th} \mathrm{a}^{-1}$ ) on the $\mathrm{pH}$ and $\mathrm{Ca}^{2+}, \mathrm{Mg}^{2+}$, and $\mathrm{K}^{+}$contents in aqueous soil extracts of a dystrophic Red Latosol with coffee. The soil was sampled in the coffee rows in the following depths: 0.150.25 ; 0.35-0.45; 0.75-0.85; $1.15-1.25$, and 2.35-2.45 m, 16 months after gypsum application. The experiment consisted of four treatments: $G-0-2 t h a^{-1}$ of gypsum was applied in total area during soil preparation, with brachiaria between coffee rows; G-7 - same as in G-0 plus $7.0 t$ $h^{-1}$ of gypsum applied to the coffee rows; G-56 - same as in G-0 plus 56 t ha ${ }^{-1}$ of gypsum applied to the coffee rows; and CV-7 - same as in G-7 but without brachiaria between the coffee rows. The experiments were conducted in triplicate, in a randomized block design. After 16 months, there was a reduction of the $\mathrm{pH}$ of the soil solution in the layers 0.15-0.25, 0.35-0.45, and 0.75-0.85 m. Gypsum improved the root environment in deeper layers, increasing $\mathrm{Mg}^{2+}$ and $\mathrm{Ca}^{2+}$ concentrations in the soil solution, but reduced $\mathrm{K}^{+}$below $0.85 \mathrm{~m}$. The amounts of exchangeable $\mathrm{Ca}^{2+}$ and $\mathrm{Mg}^{2+}$ found in the soil solution were above the critical level while exchangeable $\mathrm{K}^{+}$was within the range indicated for the crop.
\end{abstract}

Index terms: basic cations, leaching, nutrient balance.

\section{INTRODUÇÃO}

O cafeeiro requer solos profundos, porosos, bem drenados, com boa retenção de umidade e teores de macro e micronutrientes distribuídos de forma adequada ao longo do perfil do solo, para que a absorção seja contínua (Guimarães \& Lopes, 1986; Malavolta et al., 1993; Sediyama et al., 2001; Matiello et al., 2008). Limitações físicas são de difícil correção, mas as químicas podem ser anuladas com o manejo adequado da fertilidade do solo, para que a planta tenha a seu dispor, durante seu ciclo de desenvolvimento, os nutrientes em quantidades adequadas para cumprir as suas funções metabólicas (Malavolta et al., 1993; Prado, 2008).

A cafeicultura nas regiões sul e centro-oeste de Minas Gerais está implantada, em sua maior parte, em solos que apresentam limitações, caracterizados pela elevada acidez, teores médios de matéria orgânica, baixa CTC, deficiência generalizada de nutrientes e elevada saturação por Al (Souza \& Ritchey, 1986; Corrêa, 1992; Bernardi et al., 2003; Oliveira et al., 2005; Diniz, 2006, Serafim et al., 2011). Essas são condições desfavoráveis à cultura que restringem a frutificação, resultando em baixa produtividade. Como forma de se corrigir a toxidez por alumínio (Al) nas camadas mais profundas do solo e permitir que o sistema radicular alcance maiores profundidades, via de regra, mais umidas, a aplicação de gesso agrícola tem sido empregada em muitas propriedades na região oeste de Minas Gerais, em associação com adubações adequadas, de forma a garantir desenvolvimento das plantas e produtividades sustentáveis.

O gesso agrícola, um subproduto da indústria de fertilizantes fosfatados, tem sido empregado para corrigir a toxidez por $\mathrm{Al}$ e elevar os teores de Ca nas camadas mais profundas do solo. Quando aplicado 
conjuntamente com o calcário, a mistura diminui o teor de $\mathrm{Al}^{3+} \mathrm{e}$ aumenta os teores de $\mathrm{Ca}^{2+}, \mathrm{Mg}^{2+} \mathrm{e} \mathrm{SO}_{4}{ }^{2-}$, em profundidade (Custódio et al., 2005; Rampim et al., 2011), pois, sendo um sal mais solúvel em água do que o carbonato, o sulfato de cálcio dissolve na água de chuva e é deslocado para o subsolo, promovendo, portanto, grande mobilidade vertical de cátions (Ernani et al., 2001; Souza et al., 2005; Raij, 2008).

$\mathrm{O}$ desbalanço entre $\mathrm{Ca}^{2+}, \mathrm{Mg}^{2+}$ e $\mathrm{K}^{+}$no solo como consequência das aplicações elevadas de gesso deve-se às relações de tamanho (raio iônico de Pauling: 0,99, 0,65 e 1,33 $\AA$, respectivamente, para $\mathrm{Ca}^{2+}, \mathrm{Mg}^{2+} \mathrm{e} \mathrm{K}^{+}$) e à carga de cada espécie $(2,02 ; 3,07$; e 0,75 , respectivamente, para $\mathrm{Ca}^{2+}, \mathrm{Mg}^{2+} \mathrm{eK}^{+}$) (Mahan, 2003). Quanto maior a densidade de carga (relação carga/ raio), mais intensa será a ligação iônica do cátion com íns de cargas opostas como $\mathrm{OH}^{-}, \mathrm{SO}_{4}{ }^{-2}$. Portanto, a facilidade de formação de sulfatos percoláveis no solo aumenta na seguinte ordem: $\mathrm{MgSO}_{4}{ }^{0}>\mathrm{CaSO}_{4}{ }^{0}>$ $\mathrm{K}_{2} \mathrm{SO}_{4}{ }^{0}$, que pode alterar em razão de incrementos na adição de gesso agrícola ou de fatores decorrentes da heterogeneidade do sistema solo.

Além disso, o $\mathrm{Ca}^{2+}$ apresenta maior energia de adsorção aos coloides do solo, quando comparado com o $\mathrm{Mg}^{2+} \mathrm{e} \mathrm{K}^{+}$. Assim sendo, o uso excessivo do gesso, não levando em consideração o balanço de cargas dos coloides do solo, o equilíbrio iônico e a capacidade de troca de cátions, pode promover expressiva lixiviação desses nutrientes ao longo do perfil do solo (Caires et al., 2003), podendo ir para além da camada onde se encontra o sistema radicular das plantas. Esse é, comumente, o motivo de maior preocupação, principalmente quanto ao uso de elevadas doses de gesso, que podem causar desbalanços e perdas de nutriente mais lixiviáveis (Caires et al., 2003; Raij, 2008). Caires et al. (1998), Soratto \& Crusciol (2008) e Serafim et al. (2012) relataram lixiviação intensa de $\mathrm{Mg}^{2+} \mathrm{e} \mathrm{K}^{+}$ao longo do perfil do solo, ocasionada pela aplicação de elevadas doses de gesso.

Diante disso, o objetivo deste estudo foi avaliar o efeito de elevadas doses de gesso $\left(0,7\right.$ e $\left.56 \mathrm{t} \mathrm{ha}^{-1}\right)$ nos teores de $\mathrm{Ca}^{2+}, \mathrm{Mg}^{2+}, \mathrm{K}^{+}$e $\mathrm{pH}$ na solução de um Latossolo Vermelho distrófico, cultivado com cafeeiro.

\section{MATERIAL E MÉTODOS}

A área experimental está localizada na Fazenda AP Família, pertencente à Empresa Agropecuária Piumhi Ltda, no Município de São Roque de Minas, localizada na região fisiográfica do Alto São Francisco, centro-oeste do Estado de Minas Gerais, com latitude e longitude aproximadas de $20^{\circ} 14^{\prime} 42^{\prime \prime}$ de latitude sul e $46^{\circ} 21^{\prime} 57^{\prime \prime}$ de longitude oeste. O clima da região é do tipo Cwa, segundo Köppen, sendo a precipitação pluvial média anual de $1.344 \mathrm{~mm}$, com estação seca bem definida nos meses de maio a setembro; temperatura média anual de $20,7^{\circ} \mathrm{C}$; umidade relativa média de $60 \%$; e altitude média de 900 m (Menegasse et al., 2002).

Para a implantação das lavouras cafeeiras do cultivar Catucaí Amarelo Multilínea na área estudada, foi feito o preparo do solo com arado de discos e grade niveladora, regulados para profundidade de corte de $0,20 \mathrm{~m}$, aproveitando o revolvimento para incorporação de calcário e gesso agrícola nessa camada. A aplicação desses insumos ocorreu em setembro de 2008 e suas respectivas quantidades foram calculadas com base nos resultados das análises químicas e físicas do solo, segundo a recomendação para o Estado de Minas Gerais (Guimarães et al., 1999). O gesso, no preparo do solo, foi distribuído a lanço, na quantidade de 2 tha $^{-1}$, correspondendo a $50 \%$ da recomendação, com base no teor de argila do solo, de acordo com a análise de solo, considerando a camada de 0-0,10 m. Após o preparo, foi implantada Urochloa ruziziensis como cultura de cobertura do solo.

No preparo do sulco de plantio, fez-se uma operação com um subsolador florestal mono-haste, a $0,6 \mathrm{~m}$, seguida da operação com uma cavadeira dotada de sistema de enxada rotativa, que revolve o solo numa faixa de 0,5 $\mathrm{m}$ de largura e $0,6 \mathrm{~m}$ de profundidade, realizando conjuntamente a mistura dos adubos previamente colocados na linha de plantio. Em maio de 2009, sete meses após o plantio, foi realizada a aplicação em superfície dos tratamentos com gesso agrícola na linha da cultura, em uma faixa de $0,5 \mathrm{~m}$ de largura. A operação seguinte foi a chegada de solo na linha do cafeeiro, utilizando lâmina traseira do trator alinhada a $45^{\circ}$ com a linha. Essa operação cobriu todo o gesso colocado superficialmente na linha da cultura. Inicialmente, a leira formada com a amontoa chegou a 0,50 m de altura; com o tempo, ocorreu a acomodação do material, que se estabilizou com 0,20 $0,30 \mathrm{~m}$ de altura.

Os dados pluviométricos foram obtidos por meio de pluviômetros instalados na área de estudo. Realizaram-se leituras diárias no período entre 2008 e 2010. Em 2008, as leituras foram coletadas a partir de setembro e, nos demais anos, a partir de janeiro. Os dados obtidos foram: 694, 1060,5 e $745 \mathrm{~mm}$, respectivamente, para 2008, 2009 e 2010.

Foram utilizados quatro tratamentos com três repetições, distribuídas em blocos ao acaso, conforme descritos a seguir: G-0 - gesso no preparo (aplicação ocorreu em setembro de 2008, distribuído a lanço, na quantidade de $2 \mathrm{t} \mathrm{ha}^{-1}$ ) e sem gesso na linha de plantio; G-7 - gesso adicionado durante a preparação do solo ( $2 \mathrm{t} \mathrm{ha}^{-1}$ ), na mesma condição do G-0 e $7,0 \mathrm{t} \mathrm{ha}^{-1} \mathrm{de}$ gesso na linha de plantio $\left(1,75 \mathrm{~kg} \mathrm{~m}^{-1}\right)$; G-56 - gesso adicionado durante a preparação do solo $\left(2 \mathrm{t} \mathrm{ha}^{-1}\right)$, na mesma condição do G-0 e 56 t ha-1 de gesso na linha de plantio $\left(14 \mathrm{~kg} \mathrm{~m}^{-1}\right)$ (nessas parcelas experimentais as entrelinhas de plantio foram cobertas com braquiária); e CV-7: ausência de braquiária na entrelinha, com gesso no preparo e $7 \mathrm{t} \mathrm{ha}^{-1}$ de gesso na linha $\left(1,75 \mathrm{~kg} \mathrm{~m}^{-1}\right)$. Para o estudo dos teores de 
Quadro 1. Análise textural e resultados do ataque sulfúrico para os horizontes Ap e Bw do Latossolo Vermelho distrófico em estudo

\begin{tabular}{cccccccccc}
\hline Horizonte & Argila & Silte & Areia & $\mathbf{S i O}_{\mathbf{2}}$ & $\mathbf{A l}_{\mathbf{2}} \mathbf{O}_{\mathbf{3}}$ & $\mathbf{F e}_{\mathbf{2}} \mathbf{O}_{\mathbf{3}}$ & $\mathbf{P}_{\mathbf{2}} \mathbf{O}_{\mathbf{5}}$ & $\mathbf{K i}^{(\mathbf{1})}$ & $\mathbf{K r}^{(\mathbf{2})}$ \\
\cline { 2 - 7 } & \multicolumn{7}{c}{} & \multicolumn{7}{c}{$\mathrm{g} \mathrm{kg}^{-1}$} & & & & \\
$\mathrm{AP}$ & 793 & 198 & 39 & 102 & 355 & 157 & 1,32 & 0,49 & 0,38 \\
$\mathrm{Bw}$ & 819 & 148 & 33 & 105 & 392 & 169 & 0,98 & 0,46 & 0,36 \\
\hline
\end{tabular}

${ }^{(1)} \mathrm{Ki}$ : relação molecular $1,7 \times \mathrm{SiO}_{2} / \mathrm{Al}_{2} \mathrm{O}_{3} ;{ }^{(2)} \mathrm{Kr}$ : relação molecular $\left[1,7 \times \mathrm{SiO}_{2} /\left(\mathrm{Al}_{2} \mathrm{O}_{3}+\left(0,64 \times \mathrm{Fe}_{2} \mathrm{O}_{3}\right)\right]\right.$.

Quadro 2. Caracterização química do Latossolo Vermelho distrófico. Amostras de solo coletadas em setembro de 2008 antes do plantio do cafeeiro, na área com braquiária (CB) e sem braquiária (SB), na entrelinha de plantio, nas profundidades avaliadas

\begin{tabular}{|c|c|c|c|c|c|c|c|c|c|c|c|c|c|c|}
\hline Solo & Prof. & $\mathbf{p} \mathbf{H}^{(\mathbf{1})}$ & $\mathbf{P}^{(2)}$ & $\mathbf{K}^{(\mathbf{2})}$ & $\mathbf{N a} \mathbf{a}^{(2)}$ & $\mathbf{C a}^{2+(3)}$ & $\mathrm{Mg}^{2+(3)}$ & $\mathrm{Al}^{3+(3)}$ & $\mathbf{H}+\mathbf{A} \mathbf{l}^{(4)}$ & $\mathbf{t}$ & $\mathbf{T}$ & $\mathbf{v}$ & $\mathbf{m}$ & MO $^{(5)}$ \\
\hline \multicolumn{3}{|c|}{$\mathrm{m}$} & \multicolumn{3}{|c|}{$\mathrm{mg} \mathrm{dm}{ }^{-3}$} & \multicolumn{6}{|c|}{$-\mathrm{cmol}_{\mathrm{c}} \mathrm{dm}^{-3}$} & \multicolumn{2}{|c|}{$-\%$} & dag $\mathrm{kg}^{-1}$ \\
\hline \multirow[t]{4}{*}{$\mathrm{CB}$} & $0-0,20$ & 4,9 & 5,6 & 29,3 & 5,9 & 1,4 & 0,6 & 0,2 & 5,5 & 2,4 & 7,7 & 27,6 & 8,5 & 3,3 \\
\hline & $0,20-0,40$ & 5,0 & 2,5 & 20,9 & 4,8 & 0,9 & 0,3 & 0,2 & 5,3 & 1,5 & 6,5 & 18,6 & 17,9 & 3,1 \\
\hline & $0,40-0,60$ & 5,1 & 1,6 & 18,4 & 5,2 & 0,8 & 0,3 & 0,2 & 5,0 & 1,3 & 6,1 & 18,0 & 14,3 & 2,9 \\
\hline & $0,60-0,80$ & 5,0 & 3,2 & 22,9 & 5,3 & 1,0 & 0,4 & 0,2 & 5,3 & 1,7 & 6,8 & 21,4 & 13,6 & 3,1 \\
\hline \multirow[t]{4}{*}{ SB } & $0-0,20$ & 5,1 & 4,9 & 26,8 & 6,4 & 1,9 & 0,8 & 0,1 & 4,6 & 2,9 & 7,4 & 36,9 & 5,8 & 3,4 \\
\hline & $0,20-0,40$ & 5,0 & 2,1 & 19,3 & 6,4 & 1,1 & 0,5 & 0,2 & 5,0 & 1,8 & 6,6 & 25,1 & 9,9 & 3,1 \\
\hline & $0,40-0,60$ & 5,1 & 2,2 & 19,7 & 5,7 & 1,2 & 0,5 & 0,2 & 4,3 & 1,9 & 6,0 & 29,3 & 9,3 & 3,0 \\
\hline & $0,60-0,80$ & 5,1 & 1,0 & 11,5 & 3,7 & 0,5 & 0,2 & 0,1 & 4,1 & 0,8 & 4,8 & 13,9 & 17,4 & 2,4 \\
\hline
\end{tabular}

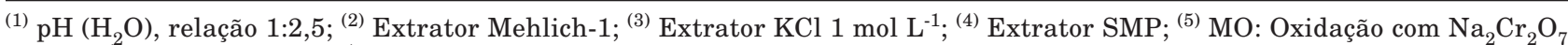
$2 \mathrm{~mol} \mathrm{~L}^{-1}+\mathrm{H}_{2} \mathrm{SO}_{4} 5 \mathrm{~mol} \mathrm{~L}^{-1}$.

$\mathrm{Ca}^{2+}, \mathrm{Mg}^{2+}, \mathrm{K}^{+}$e pH na solução do solo, o solo foi amostrado nas profundidades de $0,15-0,25 ; 0,35$ 0,$45 ; 0,75-0,85 ; 1,15-1,25$; e $2,35-2,45 \mathrm{~m}$, na linha de cada tratamento, após 16 meses da aplicação do gesso agrícola, totalizando 60 amostras. Essas amostras foram posteriormente secas ao ar (TSFA), destorroadas, passadas em peneira de $2 \mathrm{~mm}$ de abertura de malha e acondicionadas em sacos plásticos. Armazenaram-se as amostras à sombra e à temperatura ambiente até a realização das análises.

Para a extração da solução do solo, utilizou-se o método de pasta de solo saturado, adaptado do extrato aquoso (Wolt, 1994). Para isso, foi adicionada água ultrapura, lentamente, em $300 \mathrm{~g}$ de solo até atingir o ponto de saturação. Em seguida, a pasta foi deixada por $16 \mathrm{~h}$ em repouso e, após esse tempo, foi colocada em um conjunto de funil de buchner, contendo papelfiltro (filtração rápida), acoplado a um kitassato. A solução foi extraída sob vácuo por cerca de $9 \mathrm{~h}$; posteriormente, filtrada em membrana de celulose de $0,45 \mu \mathrm{m}$ de malha e armazenada para análise. Determinaram-se nas soluções o $\mathrm{pH}$ e as concentrações

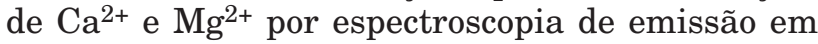
plasma com detecção ótica (ICP- AES axial da marca Varian, modelo Vista MPX com nebulizador
Meinhart), utilizando soluções-padrão para curva de calibração e de verificação da calibração, rastreadas ao NIST; $\mathrm{K}^{+}$foi determinado por fotometria de chama. Os limites de detecção foram $1 \mathrm{mg} \mathrm{L}^{-1}$, para $\mathrm{K}^{+} ; 0,12$ $\mathrm{mg} \mathrm{L}{ }^{-1}$, para $\mathrm{Ca}^{2+}$; e $0,25 \mathrm{mg} \mathrm{L}^{-1}$, para $\mathrm{Mg}^{2+}$.

Os resultados da análise textural e do extrato de ataque sulfúrico e as principais características químicas do solo estudado antes do plantio do cultivar Catucaí Amarelo Multilínea encontram-se nos quadros 1 e 2 . Tendo em vista os valores dos índices $\mathrm{Ki}$ e $\mathrm{Kr}<$ 0,75, o Latossolo em estudo foi classificado como Latossolo Vermelho distrófico típico de mineralogia gibbsítico-oxídico (Embrapa, 2006). Trata-se de um solo altamente intemperizado, permeável e com textura muito argilosa. As quantidades de corretivos e adubos utilizados nas épocas de plantio, na formação e produção da lavoura podem ser encontradas em Serafim et al. (2011).

Os resultados das análises dos atributos químicos da solução do solo foram submetidos à análise de variância. Realizaram-se as comparações das médias pelo teste de Scott-Knott, adotando-se valores de $\mathrm{p} \leq 0,05$ como critério de significância de $\mathrm{F}$ e de diferença entre médias. Os dados foram processados, utilizando-se o software SISVAR 5.1 Build 72 (Ferreira, 2000). 


\section{RESULTADOS E DISCUSSÃO}

Observa-se, na figura 1, que os valores de $\mathrm{pH}$ na solução do solo variaram entre 4,5 e 6,2. A adição de gesso, independentemente da dose aplicada, reduziu o $\mathrm{pH}$ na solução do solo nas profundidades de $0,15-0,25$; 0,35-0,45; e 0,75-0,85 m, comparativamente ao tratamento G-0. Resultados semelhantes foram encontrados por Silveira et al. (2008) e Leite et al. (2012), os quais observaram em seus trabalhos com solos salinos e sódicos que o gesso reduziu o $\mathrm{pH}$ do solo, comparado ao solo original. Essa redução no pH não ocorreu pela ação química do gesso, que é aprótico, mas pela percolação da água por meio do solo com elevada permeabilidade e, dessa maneira, lixiviando ânions hidroxilas, carbonatos e bicarbonatos (Lucena et al., 1990; Leite et al., 2012). Borges et al. (1998), ao estudarem as alterações no $\mathrm{pH}$ em um Latossolo Vermelho-Escuro álico, verificaram que as aplicações crescentes de gesso $\left(0,0 ; 3,25 ; 6,50\right.$ e $\left.9,75 \mathrm{t} \mathrm{ha}^{-1}\right)$ reduziram o $\mathrm{pH}$ do solo de 5,3 para 4,8. Segundo esses autores, essa redução do $\mathrm{pH}$ pode estar relacionada com a predominância de microrganismos anaeróbicos. Além da baixa atividade decompositora, os produtos da degradação da matéria orgânica podem ser de caráter mais ácido, contribuindo, desse modo, para o abaixamento do pH. Ernani et al. (2001), ao avaliarem as alterações na fase sólida e na solução percolada em dois solos ácidos (Latossolo Bruno álico e Cambissolo Húmico álico), verificaram que a adição de gesso agrícola diminuiu o $\mathrm{pH}$ na solução percolada e da fase

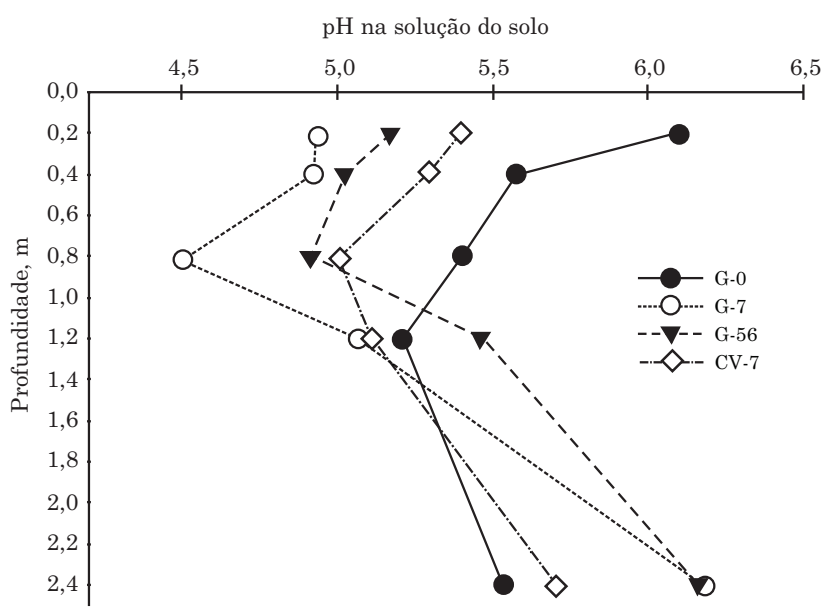

Figura 1. Valores de pH na solução do Latossolo Vermelho distrófico em função das doses de gesso utilizadas (G-0: gesso no preparo e sem gesso na linha de plantio; G-7: gesso no preparo e 7 t ha-1 $^{-1}$ de gesso na linha de plantio; G-56: gesso no preparo e $56 \mathrm{t} \mathrm{ha}^{-1}$ de gesso na linha de plantio; e CV-7: ausência de braquiária na entrelinha com gesso no preparo e $7 \mathrm{t} \mathrm{ha}^{-1} \mathrm{de}$ gesso na linha de plantio) e das profundidades amostradas de solo $(0,15-0,25 ; 0,35-0,45 ; 0,75$ 0,$85 ; 1,15-1,25$; e 2,35-2,45 m). sólida. Os autores atribuíram essa diminuição de $\mathrm{pH}$ à hidrólise do $\mathrm{Al}$, deslocado das cargas negativas pelo Ca aplicado e também pelo aumento da concentração de eletrólitos, uma vez que esses dois solos têm predomínio de carga líquida negativa.

Apesar de muitos trabalhos apresentarem alterações de $\mathrm{pH}$ em solos em que houve aplicação de gesso agrícola, nos trabalhos realizados por Veloso et al. (1992), De Maria et al. (1993), Azevedo et al. (2004), Foloni et al. (2008), Rocha et al. (2008) e Rampim et al. (2011) essas alterações não foram observadas. A ausência de alteração no pH do solo e na solução é comportamento comumente esperado, uma vez que o gesso não é um corretivo da acidez do solo, ou seja, não aumenta o $\mathrm{pH}$ do solo por ser um sal neutro. Neste trabalho, não foi observada alteração de $\mathrm{pH}$ nas profundidades de 1,15-1,25 e 2,35-2,45 m, em razão do tempo relativamente curto para que a lixiviação das bases do solo atingisse essas profundidades.

$\mathrm{O} \mathrm{pH}$ do solo é utilizado como indicativo das condições gerais da fertilidade, pois reflete indiretamente o teor de bases existentes no solo. Assim, quanto maior for seu teor de bases, maior será a atividade de $\mathrm{Ca}^{2+}, \mathrm{Mg}^{2+}$ e $\mathrm{K}^{+}$na solução do solo e, consequentemente, menor será a atividade de íons $\mathrm{H}^{+}$, medida pelo $\mathrm{pH}$ (Quaggio, 2000). Portanto, a redução do $\mathrm{pH}$ na solução do solo nas profundidades de 0,15 0,25 a $0,75-0,85 \mathrm{~m}$, independentemente das doses de gesso aplicadas, deve-se ao deslocamento dessas bases, para as camadas mais profundas do solo. Isso foi verificado por meio da análise da solução do solo em questão, em que se observou que a aplicação de doses crescentes de gesso aumentou os teores de $\mathrm{Ca}^{2+} \mathrm{e} \mathrm{K}^{+}$ até $0,45 \mathrm{~m}$ de profundidade, quando comparada ao tratamento G-0; e os teores de $\mathrm{Mg}^{2+}$ até $0,85 \mathrm{~m}$, nos tratamentos G-7 e G-56, após 16 meses da aplicação do gesso agrícola (Figura 2). Resultados semelhantes foram encontrados por Ritchey et al. (1980), Morelli et al. (1992), Ernani \& Barber (1993), Caires et al. (2003), Saldanha et al. (2007), Rampim et al. (2011) e Serafim et al. (2012).

A aplicação do gesso agrícola proporcionou lixiviação de $\mathrm{Ca}^{2+}$ e $\mathrm{Mg}^{2+}$ no perfil do solo na forma de pulso, como pode ser visto na profundidade de 0,35 $0,45 \mathrm{~m}$. Segundo Quaggio et al. (1982) e Quaggio (2000), o movimento em forma de pulso é característico da lixiviação provocada pela gessagem (Figura 2). Já no caso do $\mathrm{K}^{+}$, essa movimentação na forma de pulso não ocorreu, pois foi sendo reduzida gradativamente em profundidade, provavelmente porque esse elemento se movimenta com maior facilidade no perfil do solo, em razão da sua menor densidade de carga. Quaggio et al. (1982) observaram que a aplicação de calcário associada a 2 t ha $^{-1}$ de gesso aumentou a concentração de $\mathrm{Ca}^{2+} \mathrm{e} \mathrm{Mg}^{2+}$ em profundidade, porém na forma de pulso, na profundidade de $0,50 \mathrm{~m}$, após 18 meses da aplicações dos produtos. De Maria et al. (1993), ao avaliarem o movimento de cátions em colunas com Latossolo Vermelho-Escuro de diferentes texturas (média e argilosa), após aplicação gesso, observaram 

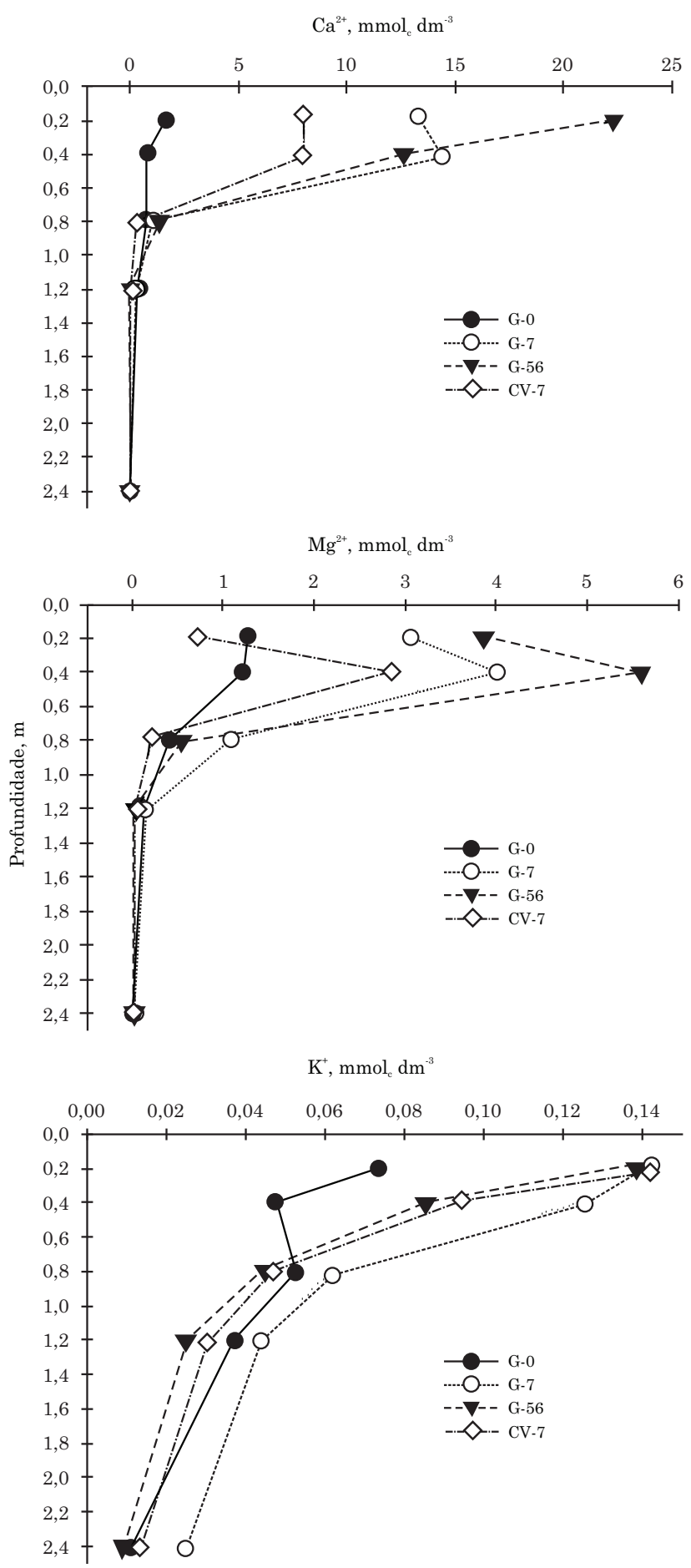

Figura 2. Efeito de doses de gesso (G-0: gesso no preparo e sem gesso na linha de plantio; G-7: gesso no preparo e $7 \mathbf{t ~ h a}^{-1}$ de gesso na linha de plantio; G-56: gesso no preparo e $56 \mathrm{t} \mathrm{ha}^{-1}$ de gesso na linha de plantio; e CV-7: ausência de braquiária na entrelinha com gesso no preparo e $7 \mathrm{t} \mathrm{ha}^{-1}$ de gesso na linha de plantio) sobre os teores trocáveis de $\mathrm{Ca}^{2+}, \mathrm{Mg}^{2+} \mathbf{e} \mathrm{K}^{+}$ $\left(\mathrm{mmol}_{\mathrm{c}} \mathrm{dm}^{-3}\right)$ na solução do solo, nas profundidades de $0,15-0,25 ; 0,35-0,45 ; 0,75$ 0,85 ; $1,15-1,25$; e 2,35-2,45 m. que as perdas de $\mathrm{Ca}^{2+}, \mathrm{Mg}^{2+} \mathrm{e} \mathrm{K}^{+}$ocorreram na forma de pulso acentuado, na primeira percolação no solo com textura média; e, na segunda percolação, com textura argilosa. Silva et al. (1997) verificaram que o movimento na forma de pulso ficou bem nítido para o $\mathrm{Mg}^{2+}$, nas amostras com aplicações de 2, 4 e $6 \mathrm{t} \mathrm{ha}^{-1}$ de gesso agrícola.

A movimentação das bases observadas neste estudo está associada à formação de pares iônicos neutros como $\mathrm{K}_{2} \mathrm{SO}_{4}{ }^{\circ}, \mathrm{CaSO}_{4}{ }^{\circ}$ e $\mathrm{MgSO}_{4}{ }^{\circ}$. Resultados semelhantes foram encontrados por Silva et al. (1998), que verificaram maior tendência de movimentação do $\mathrm{Mg}^{2+}$ em profundidade $(0,30-0,40 \mathrm{~m})$, em razão de maiores quantidades de $\mathrm{CaSO}_{4}$ aplicadas. Martins et al. (2002) observaram que o aumento das doses de gesso aplicadas ao solo decresceram os teores de $\mathrm{Mg}^{2+}$ na camada de $0-0,15 \mathrm{~m}$, aumentando nas camadas de 0,30-0,45 e de 0,45 a 0,60 m. Caires et al. (2003) constataram que, após oito e 32 meses da aplicação de gesso, houve redução de $\mathrm{Mg}^{2+}$ nas camadas superficiais do solo e aumento das concentrações do nutriente em camadas subsuperficiais. Rampim et al. (2011) concluíram que o uso do gesso em doses de 1 a $5 \mathrm{t} \mathrm{ha}^{-1}$ proporcionou redução linear de $\mathrm{K}^{+}$até $0,10 \mathrm{~m}$ e de $\mathrm{Mg}^{2+}$ até $0,40 \mathrm{~m}$ de profundidade do solo, um ano após a sua aplicação. Serafim et al. (2012), ao estudarem a movimentação de íons dos horizontes $\mathrm{A}$ e Bw de um Latossolo gibbsítico, sob seis doses de gesso agrícola $\left(0,3,6,9,12\right.$ e 15 t ha $\left.^{-1}\right)$, verificaram que após 62 dias da aplicação do gesso houve lixiviação de $\mathrm{Mg}^{2+}$ do horizonte A.

Concentrações de $\mathrm{K}^{+}$na solução do solo entre 0,003 $0,12 \mathrm{mmol}_{\mathrm{c}} \mathrm{dm}^{-3}$ têm sido indicadas como valores críticos para o desenvolvimento das culturas; para o $\mathrm{Ca}^{+2}$, valores entre $0,01-2 \mathrm{mmol}_{\mathrm{c}} \mathrm{dm}^{-3}$; e para o $\mathrm{Mg}^{2+}$, entre $0,02-0,8 \mathrm{mmol}_{\mathrm{c}} \mathrm{dm}^{-3}$ (Malavolta, 2006). Os teores de $\mathrm{K}^{+}$se mantiveram sempre dentro do valor crítico; além disso, o gesso não influenciou nos teores de $\mathrm{K}^{+}$ no solo (Quadro 3). O gesso agrícola é constituído basicamente por $\mathrm{S}, \mathrm{Ca}, \mathrm{P}_{2} \mathrm{O}_{5}$ e F (Dias, 1992), ou seja,

Quadro 3. Teores médios de $\mathrm{K}^{+}, \mathrm{Ca}^{2+}$ e $\mathrm{Mg}^{2+}$ na solução do Latossolo estudado, considerando as diferentes doses de gesso aplicadas

\begin{tabular}{cccc}
\hline Tratamento & $\mathbf{K}^{+}$ & $\mathbf{C a}^{2+}$ & $\mathbf{M g}^{2+}$ \\
\cline { 2 - 4 } G-0 $^{(1)}$ & $0,04 \mathrm{a}$ & $0,9 \mathrm{c}$ & $0,6 \mathrm{~b}$ \\
G-7 & $0,08 \mathrm{a}$ & $7,2 \mathrm{a}$ & $1,6 \mathrm{a}$ \\
G-56 & $0,06 \mathrm{a}$ & $9,1 \mathrm{a}$ & $2,0 \mathrm{a}$ \\
CV-7 & $0,07 \mathrm{a}$ & $4,1 \mathrm{~b}$ & $0,8 \mathrm{~b}$ \\
\hline
\end{tabular}

Médias seguidas de mesma letra, na coluna, não diferem entre si pelo teste de Scott-Knott $(\mathrm{p} \leq 0,05) .{ }^{(1)} \mathrm{G}-0$ : gesso no preparo e sem gesso na linha de plantio; G-7: gesso no preparo e $7 \mathrm{t} \mathrm{ha}^{-1}$ de gesso na linha de plantio; G-56: gesso no preparo e $56 \mathrm{t} \mathrm{ha}^{-1}$ de gesso na linha de plantio; e CV-7: ausência de braquiária na entrelinha com gesso no preparo e $7 \mathrm{t} \mathrm{ha}^{-1}$ de gesso na linha de plantio. 
não é fonte imediata de K ao solo. Segundo Ernani et al. (2007), a concentração de $\mathrm{K}^{+}$em solos, mesmos naqueles bem fertilizados, é normalmente inferior a $0,5 \mathrm{mmol}_{\mathrm{c}} \mathrm{dm}^{-3}$. Resultados semelhantes foram encontrados por Custódio et al. (2005), Neis et al. (2010) e Rampim et al. (2011). Serafim et al. (2012) verificaram que o $\mathrm{K}^{+}$evidenciou redução do seu teor residual no solo com a aplicação de gesso. Segundo esses autores, o gesso, um composto que contém $\mathrm{Ca}^{2+}$, pode deslocar o $\mathrm{K}^{+}$de seus sítios na argila do solo e este ser lixiviado pela água de irrigação ou de precipitação pluvial.

Os teores de $\mathrm{Ca}^{+2}$ e $\mathrm{Mg}^{2+}$ na solução do solo estão acima dos níveis críticos estipulados em literatura (0,01-2 $\mathrm{mmol}_{\mathrm{c}} \mathrm{dm}^{-3}$, para $\mathrm{Ca}^{+2}$, e $0,02-0,8 \mathrm{mmol}_{\mathrm{c}} \mathrm{dm}^{-3}$, para o $\left.\mathrm{Mg}^{2+}\right)$, nos tratamentos com gesso na linha de plantio (Quadro 3). Entre os tratamentos com gesso, os teores de $\mathrm{Ca}^{2+} \mathrm{e} \mathrm{Mg}^{2+}$ na solução do solo se elevaram, quando comparado ao tratamento somente com gesso no preparo (G-0) (Quadro 3). Resultados semelhantes foram encontrados por vários autores (Ritchey et al., 1980; Morelli et al., 1992; Ernani \& Barber, 1993; Leandro et al., 1996; Caires et al., 2003; Saldanha et al., 2007; Rampim et al., 2011; Serafim et al., 2012), os quais verificaram que a aplicação de doses de gesso provocou aumento nos teores de $\mathrm{Ca}^{2+}{\mathrm{e} \mathrm{Mg}^{2+} \text { nas }}^{2}$ camadas subsuperficiais do solo. Esse aumento ocorreu em razão da formação dos pares iônicos neutros como $\mathrm{MgSO}_{4}{ }^{\circ}$ e $\mathrm{CaSO}_{4}{ }^{\circ}$ pela dissolução do gesso incorporado ao solo, promovendo grande mobilidade desses cátions para camadas mais profundas (Dias, 1992; Cremon et al., 2009).

Os teores de $\mathrm{Ca}^{2+}$ e $\mathrm{Mg}^{2+}$ na solução do solo no tratamento G-7 com cultivo da Urochloa ruziziensis na entrelinha foram maiores que no tratamento CV-7, sem cultivo de braquiária na entrelinha (Quadro 3). Já é bem conhecida a importância da cultura de cobertura e a manutenção dos seus restos culturais na superfície do solo, tendo como consequência 0 aporte de matéria orgânica (MO) na superfície e em profundidade. Os compostos orgânicos do solo são formados por ácidos húmicos e fúlvicos e ácidos orgânicos de baixa massa molecular, responsáveis pela adsorção de íons e disponibilização desses para a solução do solo, consequentemente suprindo as plantas (Franchini et al., 2003; Pavinato et al., 2008). Andrade et al. (2012) também verificaram que o sistema de semeadura direta manteve maior teor de $\mathrm{MO}$ do que o preparo convencional, o que favoreceu a adsorção de

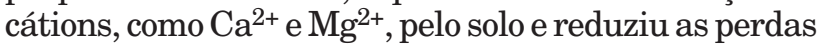
desses por erosão e lixiviação.

Diante dos resultados encontrados, observou-se que tanto a prática da calagem, visando à correção da acidez do solo, como a da gessassem, no fornecimento de $\mathrm{Ca}^{2+}$ e $\mathrm{Mg}^{2+}$ em subsuperfície e redução de $\mathrm{Al}^{3+}$, devem ser feitas em níveis exigidos pelas culturas, procurando garantir o fornecimento adequado de cálcio, magnésio e potássio. A ausência ou o excesso de qualquer um deles e o uso inadequado de calcário e gesso acarretam ao longo do tempo, em baixas produções, baixa qualidade da cultura e influenciam o crescimento e o desenvolvimento; em muitos casos, perdas irrecuperáveis.

\section{CONCLUSÕES}

1. A redução do $\mathrm{pH}$ na solução do solo nas profundidades de $0,15-0,25 ; 0,35-0,45$; e $0,75-0,85 \mathrm{~m}$ foi observada, após 16 meses da adição de gesso.

2. A aplicação de gesso agrícola foi eficiente na melhoria do ambiente radicular no subsolo, aumentou a concentração de $\mathrm{Mg}^{2+} \mathrm{e} \mathrm{Ca}^{2+}$ na solução do solo, mas reduziu o $\mathrm{K}^{+}$em profundidade, a partir de $0,85 \mathrm{~m}$.

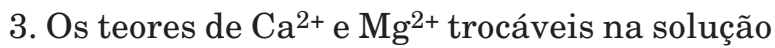
do solo estiveram acima do nível crítico; entretanto, os teores de $\mathrm{K}^{+}$trocável se mantiveram na faixa do valor crítico indicados para o desenvolvimento da cultura.

\section{AGRADECIMENTOS}

À FAPEMIG, à CAPES, ao CNPq, à EPAMIG e à Empresa AP, pelas bolsas de estudos e de pesquisa concedidas, pelo apoio financeiro e suporte logístico.

\section{LITERATURA CITADA}

ANDRADE, A.P.; MAFRA, A.L.; PICOLLA, C.D.; ALBUQUERQUE, J.A. \& BERTOL, I. Atributos químicos de um Cambissolo Húmico após 12 anos sob preparo convencional e semeadura direta em rotação e sucessão de culturas. R. Ci. Rural, 42:814-821, 2012.

AZEVEDO, W.R.; FAQUIN, V.; FERNANDES, L.A. \& OLIVEIRA JUNIOR, A.C. Disponibilidade de fósforo para o arroz inundado sob efeito residual de calcário, gesso e esterco de curral aplicados na cultura do feijão. R. Bras. Ci. Solo, 28:995-1004, 2004.

BERNARDI, A.C.C.; MACHADO, P.L.O.A.; FREITAS, P.L.; COELHO, M.R.; LEANDRO, W.M.; OLIVEIRA JÚNIOR, J.P.; OLIVEIRA, R.P.; SANTOS, H.G.; MADARI, B.E. \& CARVALHO, M.C.S. Correção do solo e adubação no sistema de plantio direto nos cerrados. Rio de Janeiro, Embrapa Solos, 2003. 22p. (Documentos, 46)

BORGES, E.N.; LOMBARDI NETO, F.; COSTA, L.M.; CORRÊA, G.F. \& BORGES, E.V.S. Alterações nos componentes da acidez do solo promovidas em camada subsuperficial compactada pela aplicação superficial de gesso. R. Ceres, 45:55-64, 1998.

CAIRES, E.F.; BLUM, J.; BARTH, G.; GARBUIO, F.J. \& KUSMAN, M.T. Alterações químicas do solo e resposta da soja ao calcário e gesso aplicados na implantação do sistema plantio direto. R. Bras. Ci. Solo, 27:275-286, 2003. 
CAIRES, E.F.; CHUEIRI, W.A.; MADRUGA, E.F. \& FIGUEIREDO, A. Alterações de características químicas do solo e resposta da soja ao calcário e gesso aplicados na superfície em sistema de cultivo sem preparo do solo. R. Bras. Ci. Solo, 22:27-34, 1998.

CORRÊA, J.B. Associação calcário/gesso na melhoria das condições químicas do solo para cafeeiros (Coffea arabica L.) em crescimento. Lavras, Universidade Federal de Lavras, 1992. 104p. (Dissertação de Mestrado)

CREMON, C.; ROSA JÚNIOR, E.J.; SERAFIM, M.E. \& ONO, F.B. Análise micromorfométrica de agregados de um Latossolo Vermelho distroférrico em diferentes sistemas de manejo. Acta. Sci. Agron., 31:139-146, 2009.

CUSTÓDIO, D.P.; OLIVEIRA, I.P.; COSTA, K.A.; SANTOS, R.S.M. \& FARIA, C.D. Avaliação do gesso no desenvolvimento e produção do capim tanzânia. R. Ci. Animal Bras., 6:27-34, 2005.

DE MARIA, I.C.; ROSSETTO, R.; AMBROSANO, E.J. \& CASTRO, O.M. Efeito da adição de diferentes fontes de cálcio no movimento de cátions em colunas de solo. Sci. Agríc., 50:87-98, 1993.

DIAS, L.E. Uso de gesso como insumo agrícola. Seropédica, Embrapa - Centro Nacional de Pesquisa de Biologia CNPBS, 1992. 6p. (Comunicado Técnico, 7)

DINIZ, B.P.C. O Grande Cerrado do Brasil Central: Geopolítica e economia. São Paulo, Universidade de São Paulo, 2006. 231p. (Tese de Doutorado)

EMPRESA BRASILEIRADE PESQUISA AGROPECUARIA EMBRAPA. Centro Nacional de Pesquisas de Solos. Sistema brasileiro de classificação de Solos. Rio de Janeiro, Embrapa Solos, 2006. 306 p.

ERNANI, P.R. \& BARBER, S.A. Composição da solução do solo e lixiviação de cátions afetadas pela aplicação de cloreto e sulfato de cálcio em um solo ácido. R. Bras. Ci. Solo, 10:41-46, 1993.

ERNANI, P.R.; BAYER, C. \& ALMEIDA, J.A. Mobilidade vertical de cátions influenciada pelo método de aplicação de cloreto de potássio em solos com carga variável. R. Bras. Ci. Solo, 31:393-402, 2007.

ERNANI, P.R.; RIBEIRO, M.S. \& BAYER, C. Modificações químicas em solos ácidos ocasionadas pelo método de aplicação de corretivos da acidez e de gesso agrícola. Sci. Agríc, 58:825-831, 2001.

FERREIRA, D.F. Análise estatística por meio do SISVAR (Sistema para Análise de Variância) para Windows versão 5.1. In: Reunião anual da região brasileira da sociedade internacional de biometria. Anais... São Carlos, Universidade Federal de São Carlos, 2000. p.255-258.

FOLONI, J.S.S.; SANTOS, D.H.; CRESTE, J.E.; CÂMARA, M. \& TIRITAN, C.S. Produção de matéria seca do milho e fertilidade do solo em função da gessagem em excesso. Coll. Agrar., 4:42-51, 2008.

FRANCHINI, J.C.; HOFFMANN-CAMPO, C.B.; TORRES, E.; MIYAZAWA, M. \& PAVAN, A. Organic composition of green manure during growth and its effect on cation mobilization in an acid Oxisol. Commun. Soil. Sci. Plant Anal., 34:2045-2058, 2003.
GUIMARÃES, P.T.G.; GARCIA, A.W.R.; ALVAREZ V., V.H.; PREZOTTI, L.C.; VIANA, A.S.; MIGUEL, A.E.; MALAVOLTA, E.; CORREAA, J.B.; LOPES, A.S.; NOGUEIRA, F.D. \& MONTEIRO, A.V.C. Cafeeiro. In: RIBEIRO, A.C.; GUIMARÃES, P.T.G. \& ALVAREZ V., V.H., eds. Recomendações para o uso de corretivos e fertilizantes em Minas Gerais: $5^{\mathrm{a}}$ aproximação. Viçosa, MG, Comissão de Fertilidade do Solo do Estado de Minas Gerais, 1999. p.289-302.

GUIMARÃES, P.T.G. \& LOPES, A.S. Solos para o cafeeiro: Características, propriedades e manejo. In: RENA, A.B.; MALAVOLTA, E.; ROCHA, M. \& YAMADA, T., eds. Cultura do cafeeiro: Fatores que afetam a produtividade. Piracicaba, Associação Brasileira para Pesquisa a Potássio e do Fosfato, 1986. p.115-156.

LEANDRO, W.M.; BELLINGIERI, P.A. \& GALON, J.A. Ação de diferentes corretivos e do gesso sobre as características químicas de um Latossolo Vermelho escuro na sucessão arroz e soja. An. Esc. Agron. Veter., 26:37-49, 1996.

LEITE, M.J.H.; SANTOS, R.V.; GOMES, A.D.V. \& VITAL, A.F.M. Aplicação de corretivos e crescimento de oleaginosas em solos salinizados do semiárido. R. Verde, 7:87-95, 2012.

LUCENA, E.R.; CAVALCANTE, L.F. \& JUNIOR, R.F. Efeito do gesso agrícola sobre a absorção de NPK e sódio por plantas de milho em um solo. Agropec. Técn., 11:54-63, 1990.

MAHAN, B.M. Química: Um curso universitário. 6.ed. São Paulo, Edgard Blücher, 2003. 581p.

MALAVOLTA, E. Manual de nutrição mineral de plantas. São Paulo, Agrônomica Ceres, 2006. 638p.

MALAVOLTA, E.; FERNANDEZ, D.R.; CASAlE, H. \& ROMERO, J.P. Seja doutor do seu cafezal. Inf. Agron., 64:1-13, 1993.

MARTINS, O.C.; NOVAIS, R.F.; ALVAREZ V., V.H.; RIBEIRO, A.C. \& BARROS, N.F. Resposta a aplicação de diferentes misturas de calcário e gesso em solos. I. Alterações químicas no perfil do solo. R. Ceres, 49:123-135, 2002.

MATIELLO, J.B.; GARCIA A.W.R. \& ALMEIDA, S.R. Adubação racional na lavoura cafeeira. Varginha, Bom Pastor, 2008. 114p.

MENEGASSE, L.N.; GONÇALVES, J.M. \& FANTINEL, L.M. Disponibilidades hídricas na Província Cárstica de ArcosPains-Doresópolis, Alto São Francisco, Minas Gerais, Brasil. R. Água Subterrâneas, 16:1-19, 2002.

MORELli, J.L.; DALBEN, A.E.; ALMEIDA, J.O.C. \& DEMATTÊ, J.L.I. Calcário e gesso na produtividade da cana-de-açúcar e nas características químicas de um Latossolo de textura média alíco. R. Bras. Ci. Solo, 16:187194, 1992

NEIS, L.; PAULINO, H.B.; SOUZA, E.D.; REIS, E.F. \& PINTO, F.A. Gesso agrícola e rendimento de grãos de soja na região do sudoeste de Goiás. R. Bras. Ci. Solo, 34:409416, 2010.

OLIVEIRA, I.P.; COSTA, K.A.P.; SANTOS, K.J.G. \& MOREIRAS, F.P. Considerações sobre a acidez dos solos de cerrado. R. Eletr. Fac. Montes Belos, 1:1-12, 2005. 
PAVINATO, P.C. \& ROSOLEM, C.A. Disponibilidade de nutrientes no solo - decomposição e liberação de compostos orgânicos de resíduos vegetais. R. Bras. Ci. Solo, 32:911920, 2008.

PRADO, R.M. Nutrição de Plantas. São Paulo, Unesp, 2008. $407 p$.

QUAGGIO, J.A. Acidez e calagem em solos tropicais. Campinas, Instituto Agronômico de campinas, 2000. 111p.

QUAGGIO, J.A.; DECHEN, A.R. \& RAIJ, B.van. Efeitos da aplicação de calcário e gesso sobre a produção de amendoim e lixiviação de bases no solo. R. Bras. Ci. Solo, 6:189-194, 1982.

RAIJ, B.van. Gesso na agricultura. Campinas, Instituto Agronômico, 2008. 233p.

RAMPIM, L.; LANA, M.C.; FRANDOLOSO, J.F. \& FONTANIVA, S. Atributos químicos de solo e resposta do trigo e da soja ao gesso em sistema semeadura direta. R. Bras. Ci. Solo, 35:1687-1698, 2011.

RITCHEY, K.D.; SOUZA, D.M.G.; LOBATO, E. \& CORREA, O. Calcium leaching to increase rooting depth in a Brazilian Savannah Oxisol. Agric. J., 72:4044,1980 .

ROCHA, A.T.; OLIVEIRA, A.C.; RODRIGUES, A.N.; LIRA JÚNIOR, M.A. \& FREIRE, F.J. Emprego do gesso do Araripe na melhoria do ambiente radicular da cana-deaçúcar. R. Bras. Ci. Agron., 3:307-312, 2008.

SALDANHA, E.C.M.; ROCHA, A.T.; OLIVEIRA, E.C.A.; NASCIMENTO, C.W.A. \& FREIRE, F.J. Uso do gesso mineral em Latosssolo cultivado com cana de açúcar. R. Caatinga, 20:36-42, 2007.

SEDIYAMA, G.C.; MELO JUNIOR, J.C.F.; SANTOS, A.R.; RIBEIRO, A.; COSTA, M.H.; HAMAKAWA, P.J.; CosTA, J.M.N. \& COSTA, L.C. Zoneamento agroclimático do cafeeiro (Coffea arabica L.) para o estado de Minas Gerais. R. Bras. Agrometeorol., 9:501509, 2001.
SERAFIM, M.E.; LIMA, J.M.; LIMA, V.M.P.; ZEVIANI, W.M. \& PESSONI, P.T. Alterações físico-químicas e movimentação de íons em Latossolo gibbsítico sob doses de gesso. Bragantia, 71:30-40, 2012.

SERAFIM, M.E.; OLIVEIRA, G.C.; OLIVEIRA, A.S.; LIMA, J.M.; GUIMARÃES, P.T.G. \& COSTA, J.C. Sistema conservacionista e de manejo intensivo do solo no cultivo de cafeeiros na região do alto São Francisco, MG: Um estudo de caso. Biosci. J., 27:964-977, 2011.

SILVA, A.A.; VALE, F.R.; FERNANDES, L.A.; FURTINI NETO, A.E. \& MUNIZ, J.A. Efeitos de relações $\mathrm{CASO}_{4} / \mathrm{CACO}_{3}$ na mobilidade de nutrientes no solo e no crescimento do algodoeiro. R. Bras. Ci. Solo, 22:451-457, 1998.

SILVA, N.M.A.; RAIJ, B.van; CARVALHO, L.H.D.; BATAGLIA, O.C. \& KONDO, J.I. Efeitos do calcário e do gesso nas características químicas do solo e na cultura do algodão. Bragantia, 56:389-401, 1997.

SILVEIRA, K.R.; RIBEIRO, M.R.; OLIVEIRA, L.B.; HECK, R.J. \& SILVEIRA, R.R. Gypsum-saturated water to reclaim alluvial saline sodic and sodic soils. Sci. Agric., 65:69-76, 2008.

SORATTO, R.P. \& CRUSCIOL, C.A.C. Atributos químicos do solo decorrentes da aplicação em superfície de calcário e gesso em sistema plantio direto recém-implantado. $R$. Bras. Ci. Solo, 32:675-688, 2008.

SOUZA, D.M.G.; LOBATO, S. \& REIN, T.A. Uso de gesso agrícola nos solos do Cerrado. Planaltina, Embrapa Cerrados, 2005. 19p. (Circular Técnica, 32)

SOUZA, D.M.G. \& RITCHEY, K.D. Uso do gesso no solo de cerrado. In: Anais do I SEMINÁRIO SOBRE O USO DE FOSFOGESSO NA AGRICULTURA, 1., Brasília, 1986, Anais... Brasília, 1986. p.119-144.

VELOSO, C.A.C.; BORGES, A.L.; MUNIZ, A.S. \& VEIGAS, I.A.J.M. Efeito de diferentes materiais no $\mathrm{pH}$ do solo. Sci. Agríc., 49:123-128, 1992.

WOLT, J.D. Obtaining soil solution: laboratory methods. In: Soil solution chemistry: applications to environmental science and agriculture. 1 ed. New York, John Wiley, 1994. 345p. 